\title{
Effect of Marital Conflict on Adolescent Anxiety: The Mediating Role of Parentification
}

\author{
Han-Na Yang ${ }^{1}$, Mi-Kyung Choi ${ }^{2}$ \\ Department of Counseling for Children, Duksung Women's University, Seoul, Korea ${ }^{1}$ \\ Department of Human Development and Family Studies, Duksung Women's University, Seoul, Korea ${ }^{2}$ \\ 부부갈등이 청소년의 불안에 미치는 영향: \\ 청소년 부모화의 매개적 역할 \\ 양한나 ${ }^{1}$, 최미경 ${ }^{2}$ \\ 덕성여자대학교 아동상담전공 ${ }^{1}$ 덕성여자대학교 아동가족학과 ${ }^{2}$
}

Objective: The main purpose of this study was to examine the relationship between marital conflict, parentification, and adolescent anxiety.

Methods: The participants comprised 301 high school students from the Seoul province. They were asked to complete questionnaires that consisted of the State-Trait Anxiety Inventory, the Children's Perception of Interparental Conflict Scale, and the Filial Responsibility Scale-Youth. The data were analyzed by frequency analysis, Cronbach's $\alpha$, descriptive statistical analysis, Pearson's correlation coefficients, multiple regression analysis, and hierarchical multiple regression analysis. To analyze the collected data, SPSS 18.0 was used.

Results: First, the content and resolution of marital conflict had an effect on both adolescent state anxiety and trait anxiety. Second, unfairness parentification had an effect on both adolescent state anxiety and trait anxiety. Third, the frequency of marital conflict had an effect on emotional parentification. Further, the intensity, content, and resolution of marital conflict had effect on unfairness parentification. Fourth, unfairness parentification played a partial mediating role in the relationship between the content of marital conflict and adolescent anxiety (state anxiety/trait anxiety). In addition, unfairness parentification played a complete mediating role in the relationship between the resolution of marital conflict and adolescent trait anxiety.

Conclusion: These results indicate that parentification plays an important role in marital conflict and adolescent anxiety. In addition, this study also shows that marital conflict has an important effect on adolescent anxiety directly. Therefore, this study will be useful for developing both parental education and counseling programs for adolescents.

Keywords: marital conflict, adolescent anxiety, parentification

\footnotetext{
서론

청소년기는 심리적으로 자기 독립과 정체성을 형성하며 성인

Corresponding Author: Mi-Kyung Choi, Department of Human Development and Family Studies, Duksung Women's University, 33 Samyangro 144-gil, Dobong-gu, Seoul, Korea

E-mail: dmkchoi@duksung.ac.kr
}

기로 향해 가는 시기이다. 이 시기 동안 일어나는 생물학적, 인지적, 사회적 변화로 인해 청소년기는 중요한 전환기로 여 겨진다(Erikson, 1968). 대다수의 청소년들이 이러한 전환기

(c)The Korean Association of Child Studies

This is an Open Access article distributed under the terms of the Creative Commons Attribution Non-Commercial License (http:// creativecommons.org/licenses/by-nc/4.0) which permits unrestricted noncommercial use, distribution, and reproduction in any medium, provided the original work is properly cited. 
를 성공적으로 보내는 반면, 일부 청소년들은 많은 고통을 경 험하기도 한다(S. I. Kang, 2007). 한국청소년상담복지개발원 의 2012년 상담경향 분석보고서를 보면 2009년 9만 20건이었 던 상담 건수가 2012년 14만 9307건으로 66\% 늘었고, 정신건 강 관련 상담은 6713 건에서 1만 3767 건으로 $100 \%$ 이상 증가 했으며 방문상담 3 천 500 건 가운데 우울증과 불안감, 자살, 자 해 등 정신건강 상담이 $25.5 \%$ (882건)로 가장 많았다. 또한 통 계청.여성가족부의 2016 청소년 통계를 보면 2014년 청소년의 사망원인은 고의적 자해가 $7.4 \%$ 로 가장 많았고, 자살생각과 관련한 여러 변인들 중 우울과 불안이 가장 강력한 매개변인 으로 언급되고 있다(B. Y. Kim, 2008; M. Kim \& Kim, 2013; D.-

K. Moon \& Kim, 2011). 이러한 결과는 우리나라 청소년들의 심리 상태가 매우 불안한 상황이며 불안이 청소년의 심리건강 적신호 중 하나로 나타나고 있음을 보여준다. 이와 같이 혼란 스럽고 불안정한 시기에 있는 청소년의 정신건강에 대한 연구 자들의 관심이 증가하면서 청소년 불안에 대한 많은 연구들이 진행되었으나 주로 시험불안, 발표불안 등의 특정불안과 사회 불안에 초점을 맞추었거나 불안과 우울의 이질성을 고려하지 않은 채 진행되었다(S.-G. Choi, 2017; J. Kim, 2011; M. H. Kim, 2017; Y. J. Lee, 2013; J. W. Yoon, 2010). 따라서 본 연구에서는 청소년이 경험하는 일반적인 불안을 중심으로 조사하였다.

불안에 대한 관심이 대두되면서 불안에 영향을 미치는 관련 변인들을 조사한 국내외 연구들(Eoh, 2005; Han, Lee, \& Row, 2014; Jeong Soo Lee, 2006; S.-M. Lee \& Yoo, 2013; Plunkett, Henry, Robinson, Behnke, \& Falcon, 2007; Shin \& Ha, 2010)이 이루어졌다. 청소년의 불안과 관련하여 주로 연구되 어 온 변인들은 개인의 특성 및 환경적 변인이었으며, 환경적 변인들로는 가정, 또래집단, 학교 등이 주로 연구되었다(Eoh, 2005; Jeong Soo Lee, 2006). 이 중 가정환경은 청소년의 불안 에 영향을 미치는 주요 변인으로 알려졌으며(S. Y. Park, Lee, Song, \& Soenens, 2008), 특히 부부갈등이 자녀의 부적응과 관 련이 깊은 변인으로 나타났다(Davies \& Cummings, 1994; Lim $\&$ Yoon, 2010). 실제로 부부갈등은 자녀의 우울, 불안과 같은 정서적 부적응과 밀접히 관련되었으며(Hwang, 2000; E. H. Song, 2005), 부부갈등을 강하게 지각할수록 자녀의 우울과 불 안이 심해졌다(A.-R. Jo, 2014). 또한 M.-K. Choi (2012)의 연구 에서도 자녀가 부모간의 부부갈등을 높게 지각할수록, 즉 부 부갈등의 강도가 높고 빈도가 잦고 잘 해결되지 않으며 갈등 의 내용이 자녀 본인에 관한 것일수록 불안이 높다는 결과가 보고되었다. 따라서 본 연구에서는 불안과 관련이 깊은 부부 갈등을 조사하였다. 한편 부부갈등과 자녀의 불안 등의 심리
적 부적응을 조사한 연구들은 주로 아동을 대상으로 이루어졌 으며 청소년을 대상으로 한 연구는 소수에 그친다(J.-Y. Kim, 2007; Jeong-Soon Lee, 2010; K. M. Yoon, 2011). 청소년기는 신 체적, 정서적, 변화들을 겪으며 혼란과 갈등을 경험하기 쉬운 시기로(Achenbach, 1991) 가족 내 갈등, 친구관계, 학업에 대한 부담감 등으로 인한 스트레스가 높고(W.-K. Choi, 2004), 특히 이 시기에 가정 내에서 부모간의 갈등을 경험할 때 청소년의 심리적 불안감이 가중될 수 있다. 따라서 본 연구에서는 발달 적으로 불안감을 느끼기 쉬운 청소년을 대상으로 가정 내 부 부갈등이 불안에 미치는 영향을 조사하였다.

부부갈등 외에 가정환경 내의 경험을 통해 자녀의 정서적 부적응을 야기할 수 있는 변인으로, 자녀가 어린 시절부터 부 모를 보살피는 역할을 맡게 되는 부모 자녀간의 역할전이인 부모화(parentification)가 주목된다(Bozormenyi-Nagy, Spark, 1973). 부모화와 관련해 Bowlby (1977)는 "역전된 부모 자녀관 계(inverted child-parent relationship)”로 그 심각성에 관해 언급 하였다. 즉, 겉으로 보기에는 바람직한 자녀 역할을 하고 있는 것 같지만, 이는 자녀가 진정으로 원한 것이 아니며 자녀의 정 신건강에 도움이 되지 않는다는 것이다(Jurkovic, 1997). 이와 같이 부모화가 여러 형태의 개인 · 가족의 역기능에 영향을 준 다는 것이 명백해지면서, 국외에서는 부모화의 결과에 대한 연구가 다양하게 수행되었다(Byng-Hall, 2002; Wells \& Jones, 2000). 부모화가 어느 정도는 정상적이며 적절할 수 있다는 것 을 주장하는 연구결과도 있지만(Earley \& Cushway, 2002), 가정 안에서 가중되었거나, 분명하게 정해져있지 않거나, 부모의 권위와 지지가 결여된 책임감은 자녀의 정신적 고통을 발생 시켰고(Kerig, 2005), 부모화된 자녀들은 종종 우울과 자기비 난 및 낮은 자아존중감을 경험하였으며 불필요한 걱정, 사회 적 소외감, 신체화 장애를 경험하였고(Byng-Hall, 2002) 수치 심과 과도한 죄의식, 피학적 성격, 자기애적 성격, 정신적 분열 을 보이기도 했다(Wells \& Jones, 2000). 또한 부모화는 내재적, 외재적 증상을 보이는 청소년이 보고한 부모-자녀 관계에서 의 낮은 온정성 및 지지에 관한 지각과도 관련이 있었다(Peris, Goeke-morey, Cummings \& Emery, 2008). 우리나라에서는 Cho (2004)가 부모화는 자녀에게 과중한 책임을 주고, 부모화된 자 녀의 행동은 가족의 암묵적인 역할기대 안에서 유지되기 쉬우 며, 부모화된 자녀들이 느끼는 불공평성과 표현되지 못한 욕 구로 인해 문제가 발생할 수 있다고 지적하였다. 부모화 경험 중에서도 특히 불공평한 경험을 한 집단이 부모와의 관계에서 과도한 책임감, 불안, 불신감, 분노, 화 등의 감정을 가지고 있 었고, 대인관계에서도 타인에게 불안을 느끼고 자기주장을 적 
절히 하지 못하며 자신의 감정을 명확히 느끼고 표현하는데 어려움을 경험했다(K. M. Kim, Lee, Jung, Jung, \& Lee, 2006). 또한 자녀가 부모화를 경험할수록 사회적 안녕감이 높아져 사 회적인 맥락에서 자신을 긍정적으로 평가한다는 부모화의 적 응적인 측면을 강조한 연구에서도, 그와 반대로 정서적 안녕 감은 낮아져 정서적인 측면에서는 부모화 경험이 자녀에게 부정적인 영향을 미친다는 것을 보고하였다(Soon Hwa Yoo, 2010). 특히 한국 사회에서는 자녀에게 효를 강조하여 부모를 공경하고 배려하며 어른의 도움 없이 혼자서도 잘하는 즉 어 른스러운 자녀가 되기를 바라는 유교적 문화가 이어져, 성인 기 이전부터 부모를 보살피는 역할을 맡게 되는 자녀들이 유 능하고 적응적인 것으로 잘못 인식되어왔다. 따라서 부모화는 국내 연구자들의 주목을 크게 받지 못했으며 국내의 부모화 관련 연구는 소수에 그치고 있다. 그러나 부모화가 자녀의 심 리적 건강에 미치는 영향이 크다는 연구가 보고되는 만큼 자 녀의 부모화, 불안과 같은 정서발달 관련 변인을 조사하는 학 문적 연구가 요구된다. 한편 국내의 부모화 관련 연구는 주로 대학생을 대상으로 이루어졌고(J. Y. Lee, 2017; Oh, 2017) 청소 년기의 부모화 관련 연구도 중학생을 대상으로 한 연구(Ham, 2015; J. H. Kim, 2017; Y. S. Park, 2016)가 주를 이룬다. 그러나 우리나라 고등학생의 경우 입시 위주의 교육에 의해 심리적인 불안감을 경험하기 쉽고 자아정체감을 확립할 여유가 없으며 그 과정에서 적응 곤란을 겪을 위험이 있어(Ko, 2007), 특히 고 등학생을 대상으로 심리적 건강에 관한 연구가 요구된다. 따 라서 본 연구에서는 고등학생을 대상으로 하여 다양한 심리사 회적인 부적응을 초래하는 부모화를 조사하였다.

한편, 구조적 가족치료에서는 부모와 자녀의 세대 간 경계 가 무너진 상태에서 부부갈등을 경험하는 자녀는 부모 중 약 자의 보호자 역할을 하게 되고, 이와 같은 가족 역동은 자녀에 게 집안에 대한 지나친 책임을 부여하고 일찍부터 성인의 역 할을 강요하며 정서적으로 가족을 돌보는 역할을 맡도록 한다 (Boszormenyi-Nagy \& Spark, 1973; Minuchin, 1974)고 하였다. 또한 부모 중 취약한 한쪽은 심지어 배우자와 같은 수준의 친 밀성을 자녀로부터 기대하며 자녀로 하여금 파트너로서의 역 할을 담당하도록 하기도 해, 결과적으로 자녀는 가족의 희생 양이 된다(Jacobvitz \& Sroufe, 1987)는 점을 강조하였다. 실제 로 부부갈등의 위험 수준을 높게 인식한 청소년이 어머니로부 터의 부모화 수준도 높게 보고하였고(Peris et al., 2008), 자녀가 지각한 부모의 부부갈등 수준과 자녀의 부모화 경험 정도가 밀접하게 관련되어 있었으며(Cho, 2004; Son, 2007), 대학생을 대상으로 한 연구에서도 자녀가 지각한 부부갈등이 높을수록
부모화 경험이 증가된다고 보고된 바 있다(S.-M. Kang, 2014; $\mathrm{Oh}, 2017)$. 그러나 부부갈등과 부모화에 관한 국내의 연구는 매우 제한적이며, 청소년을 대상으로 가정 내에서 경험하는 부부갈등이 부모화에 어떤 영향을 미치는지를 조사한 연구는 찾아보기 어렵다. 따라서 본 연구에서는 청소년이 경험하는 부부갈등과 부모화의 관계를 조사하였다.

앞서 살펴보았듯이 부부갈등이 청소년의 불안에 영향을 주 지만, 부부간의 갈등을 경험한 모든 자녀가 동일하게 문제를 가지고 있는 것은 아니며 부부간의 갈등이 자녀의 심리적 부 적응이나 문제행동과 동일하게 연결되는 것은 아님을 입증 하는 연구결과도 있다(M.-S. Kim, 2006). 많은 연구들에서 부 부갈등과 자녀의 부적응은 전반적으로 상관관계를 보이고 있 으나 직접적인 관련성은 약하므로 정확한 관련성을 보기 위 하여 조절요인이나 매개요인을 파악하여야 한다고 지적했다 (Fincham, Grych, \& Osborne, 1994). 국외에서는 부모화가 부 부갈등에 노출된 자녀의 무능감과 연관된다는 것을 보여주며, 가정 내의 폭력이 심해짐에 따라 부모화가 증가하고 결국 자 녀의 상당한 정신적 고통이 유발된다는 결과를 통해 부모화의 매개적 역할을 확인한 연구가 보고되었다(Andree \& Martin, 2011). 그러나 국내의 부부갈등과 자녀의 부적응 사이의 매개 요인 및 조절요인에 대한 연구는 자아탄력성, 사회적 지지, 부 모 양육태도, 자아존중감과 관련해 다소 제한적으로 이루어졌 다(Jang, 2006; A. Jo, 2011; Jeong-Soon Lee, 2010). 부부갈등의 영향을 받아 부모화된 행동은 유능하고 적응적으로 인식되기 때문에 유지되기 쉽고 자녀가 자신의 심리적인 문제에 대해 파악하기 어려워 문제가 더 심각해질 가능성을 안고 있으므 로, 부부갈등과 자녀의 부적응 간의 관계에서 부모화가 미치 는 결과를 조사할 필요가 있다. 따라서 본 연구는 부부갈등이 부모화를 매개로 청소년 자녀의 불안에 미치는 영향을 조사하 였다.

종합해 보면 환경적 요인인 부부갈등과 부모화는 청소년의 불안에 영향을 미치는 선행변인이며 각 변인은 서로 밀접하게 관련되어 있음을 알 수 있다. 따라서 본 연구에서는 청소년이 지각한 부부갈등 및 부모화와 청소년의 불안 간의 관계를 비 롯하여 부부갈등과 청소년의 불안, 부모화와 청소년의 불안, 부부갈등과 청소년 부모화가 서로 어떠한 영향을 미치는지 살 펴보았다. 이와 동시에 부부갈등과 청소년의 불안 간의 관계 에서 청소년 부모화의 매개적 역할도 탐색해 보았다.

\section{연구문제1}

부부갈등이 청소년의 불안에 미치는 영향은 어떠한가? 


\section{연구문제2}

부모화가 청소년의 불안에 미치는 영향은 어떠한가?

\section{연구문제3}

부부갈등이 청소년 부모화에 미치는 영향은 어떠한가?

\section{연구문제4}

부부갈등과 청소년의 불안 간의 관계에서 청소년 부모화의 매개효과는 어떠한가?

\section{연구방법}

\section{연구대상}

본 연구의 대상은 서울 $\mathrm{G}$ 구 소재의 고등학교에 재학 중인 1학 년, 2학년 남녀 청소년 301명이다. 연구 대상을 고등학생으로 선정한 이유는, 청소년기는 발달단계의 특성상 심리 사회적, 신체 생리학적 등 삶의 여러 부분에서 급격한 변화를 겪고 적 응상의 문제로 많은 어려움을 경험하기 때문이다(J.-M. Ahn $\&$ Ahn, 2012; Chae, 2001). 또한 이 시기는 부모로부터 심리적 으로 독립하려는 욕구가 강하므로 부모와의 갈등이 심해질 수 있으며(M. S. Choi \& Kang, 2008) 청소년기에 발달과업을 잘 이루지 못할 경우 정체감 혼미를 겪게 되기 때문이다(Erikson, 1968). 연구대상 청소년의 성별과 학년을 살펴보면 청소년 의 성별 구성은 총 301명 중 남자 청소년이 108명(35.9\%), 여 자 청소년이 193명(64.1\%)이었고, 학년은 1학년이 161 명 (53.5\%), 2 학년이 140 명(46.5\%)이었다. 출생순위는 둘째가 120 명(39.9\%)으로 가장 많았으며 이어서 첫째 117 명(38.9\%), 외동 40명(13.3\%), 셋째 이상 24 명(8.0\%) 순으로 나타났다. 부 의 연령은 46세 50 세가 127 명(42.2\%)으로 가장 많았고, 51 세 55세(28.2\%), 41세 45세(24.6\%), 56세 이상(3.3\%), 36세 40세(1\%)순으로 나타났다. 부의 학력은 대학교 졸업이 123 명(40.9\%)로 가장 많았으며, 고등학교 중퇴 또는 졸업(39.5\%), 전문대 졸업 또는 대학교 중퇴(10\%), 대학원 이상 $(5.3 \%)$, 초등 학교 중퇴 또는 졸업(1.3\%), 중학교 중퇴 또는 졸업 $(1 \%)$, 무학 (.3\%)순으로 나타났다. 부의 직업에 있어서는 회사원이 96 명 (31.9\%)으로 가장 많았으며, 자영업(21.9\%), 기타(12\%), 서비 스직(9.3\%), 일반 사무직(5.6\%), 일용직(5\%), 전문직(5\%), 무 직(3.7\%), 기업주(3\%)순으로 나타났다. 모의 연령은 41세 45 세가 137명(45.5\%)으로 가장 많았으며, 46세 50세(34.6\%),
51세 55세(11.6\%), 36세 40세(5.6\%), 56세 이상(2.7\%)순으 로 나타났다. 모의 학력은 고등학교 중퇴 또는 졸업이 148 명 (49.2\%)로 가장 많았고, 대학교 졸업(34.2\%), 전문대 졸업 또 는 대학교 중퇴(8.6\%), 대학원 이상 $(3.3 \%)$, 초등학교 중퇴 또 는 졸업(2.3\%), 중학교 중퇴 또는 졸업(1.3\%)순으로 나타났 다. 모의 직업에 있어서는 무직이 111 명(36.9\%)으로 가장 많 았으며, 서비스직(17.6\%), 회사원(15.9\%), 자영업(9.3\%), 기타 (8\%), 일반 사무직(4.3\%) 전문직(4\%), 일용직(1.3\%), 기업주 $(0.3 \%)$ 순으로 나타났다.

\section{연구도구}

\section{불안}

불안을 측정하기 위해 Spielberger, Gorsuch와 Lushene (1970)이 특성-상태불안을 측정하기 위해 개발한 상태-특성 불안척도 (State-Trait Anxiety Inventory [STAI])를 J. T. Kim (1978)이 한국 판으로 번안하고 표준화한 척도를 사용하였다. 본 도구의 하 위요인은 상태불안, 특성불안이며 각 20 문항씩 총 40 문항으 로 이루어져 있다. 하위요인별 문항으로 상태불안은 "나는 쉽 게 피로해진다.”, 특성불안은 “나는 긴장되어 있다.”와 같은 내 용을 포함한다. 내적합치도 계수(Cronbach's $\alpha$ ) 값은 상태불안 이 .88 , 특성불안이 .92 였다.

\section{부부갈등}

Grych, Seid와 Fincham (1992)이 아동이 부모의 갈등을 직접 평 가 하도록 고안한 도구인 '자녀가 인지한 부부갈등 척도(The Children's Perception of Interparental Conflict Scale [CPIC])'를 Kwon과 Lee (1997)가 번안하여 타당화하고 이를 다시 Seoung Hee Yoo (2001)가 청소년 자녀를 대상으로 타당도와 신뢰도를 검증한 것을 사용하였다. 이 척도는 빈도, 강도, 내용, 해결, 지 각된 위협, 대처 효율성, 자기비난, 삼각관계의 8 개 하위척도 44 문항으로 이루어져 있는데, 본 연구에서는 빈도, 강도, 내 용, 해결에 해당하는 23 문항을 사용하였다. 이는 8 가지 요인 중 빈도, 강도, 내용, 해결이 특히 자녀에게 직접적, 간접적으 로 영향을 미친다는 연구결과(Grych \& Fincham, 1990)와 자녀 의 행동문제는 부부갈등의 빈도, 강도를 높게 지각하고, 갈등 이 원만하게 해결되지 않고, 내용을 자신과 관련된 것으로 지 각할 때 더 높게 나타났다는 연구결과(Kwon \& Lee, 1999; Roh, 2005)에 근거하였다. 하위요인별 문항으로 빈도는 "우리 부모 
님은 내가 모른다고 생각하시겠지만 자주 다투시거나 의견이 맞지 않으신다.”, 강도는 “우리 부모님은 다투실 때 굉장히 화 를 많이 내신다.”, 내용은 “우리 부모님은 나의 학교일 때문에 자주 다투게 된다.", 해결은 “우리 부모님은 다투신 후에도 서 로에게 화가 나 있으시다."와 같은 내용을 포함한다. 내적합치 도 계수(Cronbach's $\alpha$ ) 값은 빈도가 .89, 강도가 .86, 내용이 .84, 해결이 .90 이었다.

\section{부모화}

부모화를 측정하기 위해 Jurkovic 등(2010)이 개발한 부모화 척 도(Filial Responsibility Scale-Youth [FRS-Y])척도를 사용하였다. 이 척도는 Jung-Sook Lee와 Kim (2007)이 번안하였고 J. Kim (2011)이 사용하였다. FRS-Y는 자기보고식 검사로서 물리적 부모화, 정서적 부모화, 공정성이라는 세 개의 하위척도로 구 분되며 총 34 문항으로 구성되어 있다. 본 연구에서는 J. Kim (2011)의 연구에서처럼 하위척도 중 공정성에 해당하는 문항 을 부모화 맥락에 맞추어 불공평성으로 역코딩하여 점수화하 였다. 하위요인별 문항으로 물리적 부모화는 "나는 종종 내 형 제들의 숙제를 도와준다.”, 정서적 부모화는 “가족들은 종종 나에게 도움을 청한다.”, 불공평성은 “우리 집에서 나는 내 몫 보다 더 많은 일을 하도록 요구 받는다.”와 같은 내용을 포함 한다. 연구대상자가 외동이거나 막내 자녀인 경우 해당되지 않는 문항은 데이터 입력 시 공란으로 처리했다. 내적합치도 계수(Cronbach's $\alpha$ ) 값은 물리적 부모화가 .73, 정서적 부모화 가. 70 , 불공평성이 .83 이었다.

\section{연구절차 및 자료분석}

본 연구를 수행하기 위해 사전에 해당 학교에 연구의 취지와 내용을 설명하여 협조를 구한 후 연구자가 학교로 직접 방문 하여 담당 교사에게 연구의 목적과 방법, 주의 사항 등에 대해 설명하였다. 담당 교사가 학생들에게 동의를 구한 후 개인 정 보 보호와 비밀보장의 원칙 등을 전달하고 2014년 12월 22일 부터 12 월 26일까지 설문을 실시하였으며 이후 연구자가 직 접 학교에 방문하여 설문지를 회수하였다. 설문지는 총 415 부 를 배부하였으며 415 부가 회수되어 $100 \%$ 의 회수율을 보였다. 이 중 응답이 누락되어 연구에 활용할 수 없는 86부(20.7\%)와 미사용 28 부(6.75\%)를 제외한 총 301 부(72.5\%)를 분석에 사 용하였다. 수집된 자료는 SPSS 18.0 을 사용하여 분석하였으며 다음과 같은 방법으로 분석하였다. 첫째, 본 연구에서 사용한
척도의 신뢰도를 알아보기 위해 Cronbach $\alpha$ 를 산출하였다. 둘 째, 변인들의 전반적인 수준을 알아보기 위해 각 변인들의 평 균, 표준편차, 최소값 및 최대값을 산출하였으며, 전체 변인들 간의 관계를 파악하기 위해 Pearson의 상관계수를 산출하였다. 셋째, 부부갈등이 청소년 불안에 미치는 영향, 부모화가 청소 년 불안에 미치는 영향, 부부갈등이 청소년 부모화에 미치는 영향을 살펴보기 위해 중다회귀 분석을 실시하였다. 넷째, 부 부갈등과 청소년 불안 간의 관계에서 청소년 부모화의 매개효 과를 검증하기 위해 Baron과 Kenny (1986)가 제안한 세 단계 접근 모델에 근거하여 위계적 회귀분석을 실시하였다.

\section{연구결과}

\section{기초분석}

\section{부부갈등 및 부모화와 청소년의 불안 간의 관계}

청소년의 성별에 따라 부부갈등 및 부모화와 불안에 차이가 있는지 알아보기 위해 $t$-test를 실시하였다. 그 결과 성별에 따 라 부부갈등, 부모화, 불안에 대한 지각에는 유의미한 차이 가 없었다. 다음으로 부부갈등 및 부모화와 청소년의 불안 간 의 관계를 살펴보았다(Table 1). 먼저 부부갈등과 청소년의 불 안 간의 상관관계를 살펴본 결과 부부갈등의 빈도, 강도, 내 용, 해결이 청소년의 상태불안과 유의한 정적 상관을 보였고 $(r=.39, p<.001 ; r=.39, p<.001 ; r=.30, p<.001 ; r=.39, p<$ $.001)$, 부부갈등의 빈도, 강도, 내용, 해결이 청소년의 특성불 안과 유의한 정적 상관을 보였다 $(r=.34, p<.001 ; r=.33, p<$ $.001 ; r=.28, p<.001 ; r=.34, p<.001)$. 다음으로 부모화와 청 소년의 불안 간의 상관관계를 살펴본 결과 부모화의 물리적 부모화, 정서적 부모화, 불공평성이 청소년의 상태불안과 유 의한 정적 상관을 보였고 $(r=.14, p<.05 ; r=.26, p<.001 ; r=$ $.33, p<.001)$, 부모화의 물리적 부모화, 정서적 부모화, 불공평 성이 청소년의 특성불안과 유의한 정적 상관을 보였다 $(r=.11$, $p<.05 ; r=.23, p<.001 ; r=.34, p<.001)$. 마지막으로 부부갈 등과 부모화 간의 상관관계를 살펴본 결과 부부갈등의 빈도, 강도, 내용, 해결은 부모화의 물리적 부모화와 유의한 정적 상 관을 보였고 $(r=.20, p<.001 ; r=.20, p<.001 ; r=.14, p<.05$; $r=.22, p<.001)$, 부부갈등의 빈도, 강도, 내용, 해결은 부모화 의 정서적 부모화와 유의한 정적 상관을 보였으며 $(r=.52, p<$ $.001 ; r=.50, p<.001 ; r=.26, p<.001 ; r=.44, p<.001)$, 부부갈 
등의 빈도, 강도, 내용, 해결은 부모화의 불공평성과 유의한 정 적 상관을 보였다 $(r=.44, p<.001 ; r=.47, p<.001 ; r=.27, p<$ $.001 ; r=.43, p<.001)$.

\section{부부갈등이 청소년의 불안에 미치는 영향}

부부갈등이 청소년의 불안에 미치는 영향을 보기 위해 중다회 귀분석을 실시하였다. 즉 부부갈등 빈도, 부부갈등 강도, 부부 갈등 내용, 부부갈등 해결을 각각 독립변인으로 하고 청소년
의 불안의 하위변인을 종속변인으로 투입하였다. 먼저 청소년 의 상태불안을 종속변인으로 투입한 결과, 부부갈등 내용, 부 부갈등 해결이 청소년의 상태불안에 유의한 영향을 미쳤으며 $(\beta=.20, p<.001 ; \beta=.21, p<.05)$ 그 설명력은 $21 \%$ 이었다. 다 음으로 청소년의 특성불안을 종속변인으로 투입한 결과, 부부 갈등 내용, 부부갈등 해결이 청소년의 특성불안에 유의한 영 향을 미쳤으며 $(\beta=.19, p<.001 ; \beta=.19, p<.05)$ 그 설명력은 $15 \%$ 이었다(Table 2).

Table 1

Correlations Among Marital Conflict, Adolescent Anxiety, and Parentification

\begin{tabular}{|c|c|c|c|c|c|c|c|c|c|}
\hline & 1 & 2 & 3 & 4 & 5 & 6 & 7 & 8 & 9 \\
\hline \multicolumn{10}{|l|}{ Marital conflict } \\
\hline 1. Frequency & - & & & & & & & & \\
\hline 2. Intensity & $.84^{* * *}$ & - & & & & & & & \\
\hline 3. Content & $.31^{* * *}$ & $.37^{* * *}$ & - & & & & & & \\
\hline 4. Resolution & $.78^{* * *}$ & $.75^{* * *}$ & $.22^{* * *}$ & - & & & & & \\
\hline \multicolumn{10}{|l|}{ Parentification } \\
\hline 5. Instrumental & $.20^{* * *}$ & $.20^{* * *}$ & $.14^{*}$ & $.22^{* * *}$ & - & & & & \\
\hline 6. Emotional & $.52^{* * *}$ & $.50^{* * *}$ & $.26^{* * *}$ & $.44^{* * *}$ & $.53^{* * *}$ & - & & & \\
\hline 7. Unfairness & $.44^{* * *}$ & $.47^{* * *}$ & $.27^{* * *}$ & $.43^{* * *}$ & $.52^{* * *}$ & $.60^{* * *}$ & - & & \\
\hline \multicolumn{10}{|l|}{ Anxiety } \\
\hline 8. State & $.39^{* * *}$ & $.39^{* * *}$ & $.30^{* * *}$ & $.39^{* * *}$ & $.14^{*}$ & $.26^{* * *}$ & $.33^{* * *}$ & - & \\
\hline 9. Trait & $.34^{* * *}$ & $.33^{* * *}$ & $.28^{* * *}$ & $.34^{* * *}$ & $.11^{*}$ & $.23^{* * *}$ & $.34^{* * *}$ & $.86^{* * *}$ & - \\
\hline$M$ & 2.78 & 2.62 & 1.92 & 2.70 & 1.56 & 1.81 & 1.84 & 2.42 & 2.32 \\
\hline$S D$ & .95 & .89 & .80 & .90 & .45 & .50 & .50 & .41 & .43 \\
\hline
\end{tabular}

Note. $N=301$.

${ }^{*} p<.05 .{ }^{* * *} p<.001$.

\section{Table 2}

Multiple Regression Analysis: Marital Conflict as a Predictor of Adolescent Anxiety ( $\beta$ )

\begin{tabular}{lcc}
\hline & Adolescent state anxiety & Adolescent trait anxiety \\
\hline Marital conflict & & .11 \\
Frequency & .11 & .06 \\
Intensity & $.20^{* * *}$ & $.19^{* * *}$ \\
Content & $.21^{*}$ & $.19^{*}$ \\
$\quad$ Resolution & .21 & .15 \\
$R^{2}$ & $19.59^{* * *}(4,296)$ & $14.55^{* * *}(4,296)$ \\
$F\left(d f_{1}, d f_{2}\right)$ &
\end{tabular}

Note. $N=301$.

${ }^{*} p<.05 .{ }^{* * *} p<.001$. 


\section{부모화가 청소년의 불안에 미치는 영향}

부모화가 청소년의 불안에 미치는 영향을 조사하기 위해 중다 회귀분석을 실시하였다. 즉 물리적 부모화, 정서적 부모화, 불 공평성을 각각 독립변인으로 하고 청소년의 불안의 하위변인 들을 종속변인으로 투입하였다. 먼저 청소년의 상태불안을 종 속변인으로 투입한 결과, 불공평성 $(\beta=.30, p<.001)$ 이 청소년 의 상태불안에 유의한 영향을 미쳤으며 그 설명력은 $11 \%$ 이었 다. 다음으로 청소년의 특성불안을 독립변인으로 투입한 결 과, 불공평성 $(\beta=.34, p<.001)$ 이 청소년의 특성불안에 유의한 영향을 미쳤으며 그 설명력은 $11 \%$ 이었다(Table 3 ).

\section{부부갈등이 청소년 부모화에 미치는 영향}

부부갈등이 부모화에 미치는 영향을 살펴보기 위해 중다회귀 분석을 실시하였다. 즉 물리적 부모화, 정서적 부모화, 불공평
성을 각각 종속변인으로 하고 부부갈등의 4 가지 하위변인들 을 독립변인으로 투입하였다. 그 결과 부부갈등 빈도 $(\beta=.31$, $p<.01)$ 가 정서적 부모화에 정적영향을 미쳤으며 그 설명력은 $29 \%$ 이었다. 또한 부부갈등의 강도, 내용, 해결이 불공평성에 영향을 미쳤으며 $(\beta=.23, p<.05 ; \beta=.13, p<.05 ; \beta=.19, p<$ $.05)$ 그 설명력은 $25 \%$ 이었다(Table 4 ).

\section{부부갈등이 청소년의 불안에 미치는 영향에서 청소년 부모화의 매개적 역할}

부부갈등과 청소년의 불안 간의 관계에서 부모화의 매개적 역 할을 알아보기 위해 Baron과 Kenny (1986)가 제안한 세 단계 접근 모델에 근거하여 회귀분석을 실시하였다. Baron과 Kenny 에 의하면, 매개변인이 되기 위한 기본조건으로 첫째, 독립변 인이 종속변인과 유의한 상관이 있어야 한다. 둘째, 독립변인 은 매개변인과 유의한 상관이 있어야 한다. 셋째, 매개변인은

Table 3

Multiple Regression Analysis: Parentification as a Predictor of Adolescent Anxiety ( $\beta$ )

Parentification

\begin{tabular}{lcc} 
Instrumental & -.08 & -.11 \\
Emotional & .12 & .08 \\
Unfairness & $.30^{* * *}$ & $.34^{* * *}$ \\
\hline$R^{2}$ & .11 & .11 \\
$F\left(d f_{1}, d f_{2}\right)$ & $13.31^{* * *}(3,297)$ & $13.78^{* * *}(3,297)$ \\
\hline
\end{tabular}

Note. $N=301$.

${ }^{* * *} p<.001$.

\section{Table 4}

Multiple Regression Analysis: Marital Conflict as a Predictors of Parentification ( $\beta$ )

\begin{tabular}{llcc}
\hline & & Parentification & \\
\cline { 2 - 4 } & Instrumental & Emotional & Unfairness \\
\hline Marital conflict & & & .06 \\
$\quad$ Frequency & .03 & $.31^{* *}$ & $.23^{*}$ \\
$\quad$ Intensity & .04 & .19 & $.13^{*}$ \\
Content & .09 & .08 & $.19^{*}$ \\
$\quad$ Resolution & .15 & .04 & .25 \\
\hline$R^{2}$ & .04 & .29 & $24.21^{* * *}(4,296)$ \\
$F\left(d f_{1}, d f_{2}\right)$ & $4.46^{* *}(4,296)$ & $31.16^{* * *}(4,296)$ & \\
\hline
\end{tabular}

Note. $N=301$.

${ }^{*} p<.05 .{ }^{* *} p<.01 .{ }^{* * *} p<.001$. 
Table 5

Hierarchical Analysis: Mediating Role of Unfairness Parentification Between Marital Conflict and Adolescent State Anxiety ( $\beta$ )

\begin{tabular}{|c|c|c|c|}
\hline & Step 1 & Step 2 & Step 3 \\
\hline Independent variables & Unfairness & State anxiety & State anxiety \\
\hline \multicolumn{4}{|l|}{ Marital conflict } \\
\hline Frequency & .06 & .11 & .10 \\
\hline Intensity & $.23^{*}$ & .06 & .03 \\
\hline Content & $.13^{*}$ & $.20^{* * *}$ & $.18^{* *}$ \\
\hline Resolution & $.19^{*}$ & $.21^{*}$ & $.19^{*}$ \\
\hline Unfairness & & & $.14^{*}$ \\
\hline$R^{2}$ & .25 & .21 & .21 \\
\hline$F\left(d f_{1}, d f_{2}\right)$ & $24.21^{* * *}(4,296)$ & $19.59^{* * *}(4,296)$ & $17.09^{* * *}(5,295)$ \\
\hline
\end{tabular}

Note. $N=301$.

${ }^{*} p<.05 .{ }^{* *} p<.01 .{ }^{* * *} p<.001$.

종속변인과 유의한 상관이 있어야 한다. 앞의 Table 1 연구변 인들 간의 상관관계를 보면 본 연구에서는 부부갈등의 4 가지 하위요인, 청소년의 불안의 2 가지 하위요인, 부모화의 3 가지 하위요인이 기본 조건에 충족되었다. 따라서 부부갈등과 청소 년의 불안 간의 관계에서 부모화의 매개적 역할에 대한 회귀 분석을 실시하였다. 회귀분석을 실시하기 전 회귀식 기본과정 인 다중공선성 위반여부를 검토하기 위해 공차(Tolerance) 및 분산팽창계수(variance inflation factor)를 확인한 결과, 각각 0.1 이상(.87 .99)과 10 이하(1.00 1.14)로 나타나 회귀분석의 실 시에 무리가 없는 것으로 판단했다(Berry \& Feldman, 1985).

부모화의 매개적 역할을 확인하기 위해 첫 번째 중다회귀 분석에서는 독립변인인 부부갈등이 매개변인인 청소년 부모 화에 미치는 영향력을 살펴보았고, 두 번째 중다회귀분석에서 는 독립변인인 부부갈등이 종속변인인 청소년의 불안에 미치 는 영향력을 살펴보았으며, 세 번째 중다회귀분석을 통해서 는 독립변인인 부부갈등과 매개변인인 청소년 부모화를 새로 운 독립변인으로 동시에 투입한 후 독립변인이 종속변인인 청 소년의 불안에 미치는 영향력의 유의성이 감소하거나 사라지 고, 매개변인이 종속변인에 유의한 영향을 미치는지를 살펴보 았다. 그 결과 부부갈등과 청소년의 불안 간의 관계에서 불공 평성의 매개적 역할이 나타났다. 그러나 부부갈등과 청소년의 불안 간의 관계에서 물리적 부모화 및 정서적 부모화의 매개 적 역할은 발견되지 않았다.

\section{부부갈등과 청소년의 상태불안 간의 관계에서 불공평성의 매개적 역할}

부부갈등과 청소년의 상태불안 간의 관계에서 불공평성의 매
개적 역할을 알아본 결과(Table 5), 첫 번째 단계에서 부부갈 등 강도, 내용, 해결은 불공평성에 영향을 미쳤으며 $(\beta=.23, p$ $<.05 ; \beta=.13, p<.05 ; \beta=.19, p<.05)$, 두 번째 단계에서는 부 부갈등 내용, 해결이 청소년의 상태불안에 유의한 영향을 미 쳤다 $(\beta=.20, p<.001 ; \beta=.21, p<.05)$. 세 번째 단계에서 부부 갈등의 강도, 내용, 해결과 불공평성을 동시에 투입하였을 때 불공평성은 청소년의 상태불안에 유의한 영향을 미쳤으며 $(\beta$ $=.14, p<.05)$, 부부갈등 내용의 영향력이 감소하였다 $(\beta=.20$, $p<.001 \rightarrow \beta=.18, p<.01)$. 즉, 불공평성은 부부갈등 내용과 청소년의 상태불안 간의 관계에서 부분매개적 역할을 하였다. 불공평성의 매개효과가 통계적으로 유의한지 알아보기 위하 여 Sobel Test를 실시한 결과 $z=3.44(p<.001)$ 로 유의하였다.

\section{부부갈등과 청소년의 특성불안 간의 관계에서 불공평성의 매개적 역할}

부부갈등과 청소년의 특성불안 간의 관계에서 불공평성의 매 개적 역할을 알아본 결과(Table 6), 첫 번째 단계에서 부부갈 등 강도, 내용, 해결은 불공평성에 영향을 미쳤으며 $(\beta=.23, p$ $<.05 ; \beta=.13, p<.05 ; \beta=.19, p<.05)$, 두 번째 단계에서는 부 부갈등 내용, 해결이 청소년의 특성불안에 유의한 영향을 미 쳤다 $(\beta=.19, p<.001 ; \beta=.19, p<.05)$. 세 번째 단계에서 부부 갈등의 강도, 내용, 해결과 불공평성을 동시에 투입하였을 때 불공평성은 청소년의 특성불안에 유의한 영향을 미쳤으며 $(\beta$ $=.19, p<.01)$, 부부갈등 내용의 영향력은 감소하였고 $(\beta=.19$, $p<.001 \rightarrow \beta=.17, p<.01)$, 부부갈등 해결은 더 이상 유의한 영향을 미치지 않았다 $(\beta=.19, p<.05 \rightarrow n s)$. 즉, 불공평성은 부 부갈등 내용과 청소년의 특성불안 간의 관계에서 부분매개적 
Table 6

Hierarchical Analysis: Mediating Role of Unfairness Parentification Between Marital Conflict and Adolescent Trait Anxiety ( $\beta$ )

\begin{tabular}{lccc}
\hline & Step 1 & Step 2 & Step 3 \\
\cline { 2 - 4 } \multicolumn{1}{c}{ Independent variables } & Unfairness & Trait anxiety & Trait anxiety \\
\hline Marital conflict & & & .10 \\
$\quad$ Frequency & .06 & .11 & -.02 \\
$\quad$ Intensity & $.23^{*}$ & .02 & $.17^{* *}$ \\
Content & $.13^{*}$ & $.19^{* * *}$ & .16 \\
$\quad$ Resolution & $.19^{*}$ & $.19^{*}$ & $.19^{* *}$ \\
Unfairness & & & .18 \\
$R^{2}$ & .25 & .15 & $13.92^{* * *}(5,295)$ \\
$F\left(d f_{1}, d f_{2}\right)$ & $24.21^{* * *}(4,296)$ & $14.55^{* * *}(4,296)$ &
\end{tabular}

Note. $N=301$.

${ }^{*} p<.05 .{ }^{* *} p<.01 .{ }^{* * *} p<.001$.

역할을 하였고, 부부갈등 해결과 청소년의 특성불안 간의 관계 에서 완전매개적 역할을 하였다. 불공평성의 매개효과가 통계 적으로 유의한지 알아보기 위하여 Sobel Test를 실시한 결과 각 각 $z=3.10$ ( $p<.001), z=3.10$ ( $p<.001)$ 으로 유의하였다.

\section{논의 및 결론}

본 연구에서는 고등학교 1,2 학년에 재학 중인 청소년을 대상 으로 부부갈등 및 부모화가 청소년의 불안에 미치는 영향 및 부부갈등이 청소년 부모화에 미치는 영향을 살펴보고, 부모화 가 부부갈등과 청소년의 불안 간의 관계에서 매개적 역할을 하는지를 탐색하였다. 본 연구의 연구문제를 중심으로 그 결 과를 요약하고 논의하면 다음과 같다.

첫째, 부모간의 갈등을 높게 지각할수록 청소년의 불안은 높았다. 즉, 부부갈등의 내용이 청소년 자신에 관한 것일수 록, 부부갈등이 원만히 해결되지 않을수록 청소년의 상태불 안과 특성불안이 높았다. 이와 같은 결과는 부부갈등이 불안, 위축, 우울, 사회적 고립과 같은 내면적인 장애와 관련이 많다 는 연구결과(N.-Y. Kim, 2016) 및 부모의 부부갈등이 자녀의 정서적 부적응과 유의미한 상관이 있다는 연구결과(Hwang, 2000), 그리고 부부갈등이 우울, 불안과 직접적으로 유의미한 상관관계를 보인 연구결과(Song, 2005)와 유사하다. 또한 이 는 부부갈등의 내용이 아동과 관련된 것일 때 아동이 분노, 수 치심, 무력감, 자책감을 더 많이 느낀다는 연구결과(S. J. Park, 1996) 및 부부갈등이 발생한 후 갈등이 해결되지 않았을 때
아동이 가장 부정적으로 반응한 연구결과와도 유사한 맥락으 로 이해할 수 있다(Cummings, Simpson, \& Wilson, 1993). 이는 부모 간 갈등의 원인이 자신이라고 지각한 청소년은 자신이 가족의 평화를 깨뜨린다는 생각에 불안을 느끼며, 부부갈등 이 발생한 후 해결이 안된 경우 청소년은 가정에서 안정감을 느끼지 못한다는 것을 뜻한다.

반면 본 연구에서 부부갈등의 빈도, 강도는 청소년의 불안 에 유의한 영향을 미치지 않았다. 이는 부모의 부부갈등이 자 녀에게 노출되는 횟수가 많고, 사소한 말다툼보다는 폭력을 행사하는 등의 격렬한 부부싸움을 목격한 자녀일수록 내재화 및 외현화 문제행동을 더 많이 일으키는 것으로 나타난 연구 결과(S.-S. Ahn, 2014), 부모의 갈등 형태가 더 심각할수록 아 동이 분노, 슬픔, 걱정, 수치심 등의 부정적인 감정을 더 많이 느끼며, 아동의 주관적인 우울감과 행동문제도 심한 것으로 나타났다는 보고(S. J. Park, 1996)와는 차이가 있다. 이는 우리 나라 청소년의 경우 학업으로 인해 집에 머무는 시간보다 밖 에서 보내는 시간이 많아 부모님의 부부갈등이 얼마나 자주 일어나는지, 얼마나 심하게 일어나는지 지각하기 어렵기 때 문인 것으로 보인다. 또한 위의 결과와 함께 고려해 볼 때, 청 소년이 부부갈등에 노출되는 시간이 적더라도 부모가 청소년 자녀의 문제로 다투거나 부부간의 갈등이 해결되지 않을 때 청소년은 부부갈등으로부터 부정적인 영향을 받을 수 있다고 이해할 수 있다. 이러한 결과는, 자녀 문제로 부부간에 갈등이 발생했을 경우 부모는 자녀가 없는 곳에서 상의하거나, 자녀 가 있다면 그 내용을 자녀에게 이해시켜주는 것이 필요함을 나타낸다. 또한 부부갈등 상황일 때 부모는 가능한 한 빨리 화 
해를 하거나, 단시간에 부부갈등이 해결되기 어려운 상황에 서는 자녀가 이해할 수 있도록 충분한 대화를 하여 청소년 자 녀가 겪을 심리적 어려움을 예방할 필요가 있음을 보여준다.

둘째, 부모화된 청소년일수록 불안이 높았다. 즉, 청소년 자 녀가 자신이 가정에서 불공평하게 책임을 맡는다고 지각할 수록 청소년의 상태불안과 특성불안이 높았다. 이와 같은 연 구결과는 부모화 경험을 많이 한 아동일수록 이후에 우울, 불 안, 물질 중독 등의 증상을 보일 가능성이 크며 부모화된 자녀 들은 병리적일 정도의 돌봄을 수행함에 따라 종종 우울과 자 기 비난 및 낮은 자아존중감 등을 경험한다는 연구결과(ByngHall, 2002) 및 부모화 경험을 많이 할수록 안녕감 수준이 낮아 진다는 연구결과(S. H. Moon, 2014), 그리고 부모화된 자녀일 수록 부모를 보살피고 베푸는 입장에서 불공평한 경험을 하고 표현되지 못한 욕구로 인해 문제가 발생 할 수 있음을 밝힌 연 구결과(Cho, 2004)와 유사한 결과이다. 또한 부모화 경험 중에 서도 특히 불공평성을 높게 경험하는 집단이 부모와의 관계에 서 과도한 책임감, 불안, 불신감, 분노, 화 등을 가지고 있는 것 으로 나타났고, 대인관계에서 타인에게 불안을 느끼고 자기 주장을 적절히 표현하지 못하며 본인의 감정을 명확히 느끼 고 표현하는데 어려움을 가지고 있다고 밝힌 연구결과(K. M.

Kim et al., 2006)와도 비슷한 맥락의 결과이다. 이는 청소년의 경우, 상황에 대한 판단과 해석이 인지적으로 가능해지기 때 문에 실제로 청소년이 가정에서 맡게 된 물리적인 일의 양이 나 가족의 정서적 욕구를 지나치게 만족시키려는 노력의 정도 보다는 그 일들을 하는 것이 적절한지 혹은 공평한지의 여부 가 청소년의 불안에 더 큰 영향을 미쳤기 때문으로 사료된다.

반면 물리적 부모화, 정서적 부모화는 청소년의 불안에 유 의한 영향을 미치지 않았다. 이는 부모화의 하위변인 중 특히, 정서적 부모화와 불공평성이 불안에 영향을 미친다는 연구결 과(M. S. Choi \& Kang, 2008)와는 일부 다른 결과이다. 이는 본 연구에서 물리적 부모화, 정서적 부모화, 불공평성을 함께 하 위요인으로 고려했을 때 물리적 부모화, 정서적 부모화에 비 해 불공평성의 영향력이 상대적으로 컸기 때문으로 이해해 볼 수 있으며, 추후 연구를 통해 지속적으로 조사해 볼 필요가 있 다. 이러한 결과는 청소년 자녀를 양육할 때 부모는 가정에서 지나치게 부모화된 청소년의 행동을 착한 행동이나 적응적인 행동으로만 받아들여 그대로 두기보다는 그러한 행동으로 가 려진 청소년 자녀의 심리적인 불안에 대해 파악하려는 노력을 할 필요가 있음을 시사한다. 특히, 가족 구성원들이 가정에서 의 일을 나누어 맡을 때에 청소년 자녀가 불공평하게 책임을 떠맡는다고 느끼지 않도록 가족 간에 충분한 대화와 조율이
필요할 것이다.

셋째, 부모간의 갈등을 높게 지각할수록 청소년은 부모화 되는 경향이 있었다. 즉, 부부갈등이 자주 일어날수록 청소년 은 가족의 정서적 욕구를 지나치게 충족시키려는 것으로 나 타났으며, 부부갈등의 강도가 세고 부부갈등의 내용이 청소 년 자신에 대한 것이며 부부갈등이 원만히 해결되지 않을수 록 청소년은 가족들이 책임을 공평하게 나누어 맡지 않는다고 보고했다. 이는 부부갈등 수준이 높으면 일차적 연합이 부부 사이에 있지 않고 부모와 자녀 사이에 있게 되면서 청소년 자 녀는 부모화 경험을 하게 되고, 특히 정서적 부모화와 불공평 성이 높아진다는 연구결과(E. J. Song, 2010) 및 부부갈등의 빈 도가 정서적 부모화를 설명하는 설명변인으로 나타난 연구결 과(Son, 2007)와 유사한 결과이다. 이는 부부갈등이 심한 부부 는 서로 간에 정서적인 욕구를 채워주기 어려워 부모 사이에 있는 자녀가 가족 구성원의 심리적 갈등을 해소하고 정서적인 욕구를 채워주고자 지나치게 노력하기 때문인 것으로 여겨진 다.

반면 부부갈등은 물리적 부모화에 유의한 영향을 미치지 않았다. 이는 부부갈등의 강도와 내용이 물리적 부모화를 설 명하는 설명변인으로 나타난 것(Son, 2007)과는 다른 연구결 과이다. 이는 본 연구의 대상이 고등학교 1학년, 2 학년의 청소 년으로 학업과 입시가 중요한 시기이기 때문에 집에서보다 학 교나 학원에서 보내는 시간이 많으며, 집에 있더라도 부모가 요리하기, 청소, 세탁, 아픈 가족 구성원 돌보기 등과 같이 일 반적으로 부모에게 기대되는 물리적 책임을 청소년 자녀에게 떠맡기지는 않았기 때문으로 사료된다. 이러한 연구결과는 부 모화된 자녀들이 부부갈등이 있는 상황에서 정서적으로 부모 를 더 많이 보살피고 불공평을 느끼게 됨을 시사한다. 따라서 부부갈등 상황에서 지나치게 부모를 위로하거나 정서적 지지 를 제공하는 청소년 및 가족 간에 역할을 불공평하게 떠맡거 나 많은 책임을 지고 있는 청소년을 양육할 때 세심한 주의를 기울여야 할 것이다.

넷째, 부부갈등과 청소년의 불안 간의 관계에서 부모화는 매개적 역할을 하는 것으로 나타났다. 즉, 불공평성은 부부갈 등 내용과 청소년의 상태불안 및 특성불안 간의 관계에서 부 분매개 역할을 하였다. 또한 불공평성은 부부갈등 해결과 청 소년의 특성불안 간의 관계에서 완전매개 역할을 하였다. 이 는 부부갈등이 일어났을 때 그에 대한 자녀의 대처 노력이 때 때로 갈등을 그치게 할 수 있지만 자녀가 직접적으로 부부갈 등에 개입하여 화해시키려 하면 부부갈등이 부모 자녀 간의 갈등으로 번져 자녀를 향한 부모의 분노나 공격이 야기 될 수 
있으며, 이로 인해 자녀는 부모가 안정적인 존재가 아니라고 지각하게 된다는 연구결과(Son, 2007) 및 자녀가 부모의 일방 적 돌봄을 받지 못하는 왜곡된 상호작용으로 인해 부모와 자 녀의 역할이 바뀌어 나타나는 부모화 현상이 나타나게 된다는 연구결과(Y. T. Kim, 2000)와 유사한 맥락으로 이해할 수 있다. 또한 부부갈등이 내재화에 미치는 영향에서 불공평성이 부분 매개 한다는 연구결과(J. Kim, 2011)와도 유사한 결과이다.

반면 물리적 부모화, 정서적 부모화는 부부갈등과 청소년 자녀의 불안 간의 관계에서 매개적 역할을 하지 않았다. 이는 부부갈등이 자녀의 내재화 부적응에 미치는 영향을 물리적 부 모화가 부분매개 한다는 연구결과(J. Kim, 2011)와 다소 다른 결과이다. 이러한 결과는 J. Kim (2011)의 연구에서 우울불안 이 내재화 부적응의 하나의 하위요인으로 포함되어 불안과 우 울의 이질성이 고려되기 어려웠던 반면 본 연구에서는 상태불 안, 특성불안에 연구의 초점을 맞추어 전반적인 불안을 조사 했기 때문으로 여겨진다. 또한 이는 부부갈등 상황에서 부모 가 청소년 자녀에게 정서적, 물리적인 역할을 요구할 때, 실제 로 그 역할을 얼마나 맡는지 보다 그것이 공평한지의 여부가 청소년의 불안에 더 큰 영향을 미쳤기 때문으로 사료된다. 이 러한 연구결과는 청소년 자녀가 단순히 부모간의 갈등으로 인 해 경험하는 불안뿐만 아니라, 부모간의 갈등 상황에서 본인 이 불공평하게 책임을 맡게 된다고 지각하며 심리내적인 갈등 과 억압된 욕구로 인해 경험하는 불안에도 주의를 기울여야 함을 시사한다. 즉, 부부갈등과 청소년 자녀의 불안 간의 관계 를 설명하는데 있어 부모화가 중요한 변인이며 이에 관한 심 층적인 추후 연구가 필요함을 보여준다.

마지막으로 본 연구결과의 제한점과 이를 근거로 한 후속 연구를 위한 제언은 다음과 같다. 첫째, 본 연구는 서울의 한 고등학교 학생을 대상으로 하였으므로 표집대상이 제한되어 있어 연구 결과를 일반화하는데 다소 무리가 있다. 둘째, 본 연 구의 자료는 청소년 자녀의 자기보고에 의해 측정되었는데 이 로 인해 그 결과가 과대, 과소평가될 수 있으며 부모의 보고와 차이를 보일 수 있다. 따라서 추후 연구에서는 청소년의 보고 뿐 아니라 부모의 보고까지 고려하여 측정해 볼 필요가 있다. 셋째, 본 연구에서는 자료 분석 시 표집대상의 사회인구학적 요인에 따른 차이를 고려하지 않았다. 따라서 추후연구에서 는 다양한 사회인구학적 요인을 고려해 분석하여 각각에 따른 차이를 살펴볼 필요가 있다. 넷째, 부부갈등과 불안 및 부부갈 등과 심리적인 부적응 간의 관계에서 부모화의 매개적 역할을 조사한 선행연구가 극히 적어, 부모화의 매개적 역할에 관한 논의가 하위요인 별로 이루어지는 데에 제한이 있었다. 특히,
물리적 부모화의 매개적 역할이 나타난 연구는 J. Kim (2011) 의 연구가 유일하고, 물리적 부모화의 매개효과에 관해 연구 결과 간의 불일치를 보이므로 이에 관한 지속적인 후속연구가 요구된다.

이러한 제한점에도 불구하고 본 연구에서 다음과 같이 몇 가지의 의의를 찾아볼 수 있다. 첫째, 청소년의 불안과 관련한 국내 연구는 일반화된 불안보다는 주로 내재화 장애, 사회불 안, 시험불안 등과 관련해 수행되었다. 또한 부모화에 관한 최 근의 국내 연구는 부족한 실정이며 연구대상이 주로 대학생 에 국한되어 있었다. 따라서 청소년 자녀를 대상으로 부부갈 등, 상태불안, 특성불안, 부모화를 살펴보았다는 점에 의의가 있다.

둘째, 부부갈등이 청소년 자녀의 불안에 영향을 미치는 과 정에서 부모화의 매개효과를 밝혔다는데 의의가 있다. 다시 말해 부부갈등 상황에서는 청소년 자녀가 가정에서 여러 역할 을 불공평하게 떠맡게 될 가능성이 높아지고, 부모가 그러한 청소년의 행동을 적응적인 행동으로 여기며 강화하면 자녀의 불안이 높아짐을 확인하였다. 여러 가지 사회적, 경제적인 상 황들이 부부갈등을 심화시키고 있으며 부부갈등을 경험하는 청소년도 증가하고 있는 현 시점에서, 본 연구결과는 부부갈 등이 청소년의 불안에 미치는 직접적인 영향뿐 아니라 부모화 를 통해 미치는 간접적인 영향에도 주의를 기울여야 할 필요 성을 제기했다. 따라서 상담 장면에서 부부갈등을 경험한 청 소년이 불안을 호소하는 경우, 상담자는 다른 탐색과 더불어 청소년이 경험한 부부갈등 및 부모화 수준을 파악함으로써 부 모를 돌보기 위해 자신에게 필요한 관심과 욕구 등을 희생하 며 어려움을 겪는 청소년을 도울 수 있을 것이다.

셋째, 본 연구 결과는 적응적인 행동이라 여겨지며 간과되 기 쉬운 부모화가 내포하고 있는 위험성을 제기하였다는 점에 큰 의의가 있다. 타인을 도우려는 행동은 충분히 적응적일 수 있지만, 자신의 욕구를 무시하면서까지 다른 가족 구성원의 욕구를 충족시키려는 청소년 자녀의 부모화된 행동은 병리적 일 수 있다. 그럼에도 그러한 행동은 철든 행동, 착한 행동으로 강화 받기 때문에 계속해서 유지되기 쉽고 그에 따라 청소년 은 자신의 심리내적인 문제에 대해 파악하지 못하게 되어 결 국 문제가 잘 드러나지 않아 더욱 위험할 수 있다. 본 연구결과 는 이처럼 적응적이라고 여겨지는 부모화된 자녀에게 정서적 인 돌봄과 양육이 필요함을 보여줌으로써 그들을 보호하도록 돕는 부모교육 프로그램의 기초자료로 활용 될 수 있을 것이 라 기대한다. 


\section{Acknowledgements}

This study was supported by the 2016 research grant of Duksung Women's University.

\section{Notes}

This article is a part of the first author's master's thesis submitted in 2015, and was presented as a poster at the 2016 Annual Fall Conference of the Korean Association of Child Studies.

\section{Conflict of Interest}

No potential conflict of interest relevant to this article was reported.

\section{References}

\section{In English}

Achenbach, T. M. (1991). The derivation of taxonomic constructs: Anecessary stage in the development of developmental psychopathology. In D. Cicchetti \& S. Toth (Eds.), Rochester symposium on Developmental psychopathology: Models and integrations (pp. 43-74). Hillsdale, NJ: Erlbaum.

Andree, F., \& Martin, D. (2011). Children's appraisals as mediators of the relationship between domestic violence and child adjustment. Violence and Victims, 26(3), 377-392.

Baron, R. M., \& Kenny, D. A. (1986). The moderator-mediator variable distinction in social psychological research: Conceptual, strategic, and statistical considerations. Journal of Personality and Social Psychology, 51(6), 1173-1182. doi:10.1037/0022-3514.51.6.1173

Berry, W. D., \& Feldman, S. (1985). Multiple regression in practice. London: Sage Publications.

Boszormenyi-Nagy, I., \& Spark, G. M. (1973). Invisible loyalties: Reciprocity in intergenerational family therapy. Oxford: Harper \& Row.

Bowlby, J. (1977). The making and breaking of affectional bonds. II. Some principles of psychotherapy. The fiftieth Maudsley lecture (expanded version). British Journal of Psychiatry, 130(5), 421-431. doi:10.1192/bjp.130.5.421

Byng-Hall, J. (2002). Relieving parentified children's burdens in families with insecure attachment patterns. Family Process, 41(3), 375-388. doi:10.1111/j.1545-5300.2002.41307.x

Cummings, E. M., Simpson, K. S., \& Wilson, A. (1993).
Children's responses to interadult anger as a function of information about resolution. Developmental Psychology, 29(6), 978-985. doi:10.1037/0012-1649.29.6.978

Davies, P. T., \& Cummings, E. M. (1994). Marital conflict and child adjustment: An emotional security hypothesis. Psychological Bulletin, 116(3), 387-411. doi:10.1037/00332909.116.3.387

Earley, L., \& Cushway, D. J. (2002). The parentified child. Clinical Child Psychology and Psychiatry, 7(2), 163-178.

Erikson, E. H. (1968). Identity: Youth and crisis. NY: Norton.

Fincham, F. D., Grych, J. H., \& Osborne, L. (1994). Does marital conflict cause child maladjustment: Directions and challenges for longitudinal research. Journal of Family Psychology, 8,(2), 128-140. doi:10.1037/0893-3200.8.2.128

Grych, J. H., \& Fincham, F. D. (1990). Marital conflict and children's adjustment: A cognitive-contextual framework. Psychological Bulletin, 108(2), 267-290. doi:10.1037/00332909.108.2.267

Jacobvits, D., \& Sroufe, L. A. (1987). The early caregiverchild relationship and attention-deficit disorder with hyperactivity in kindergarten: A prospective study. Child Development, 58(6), 1496-1504. doi:10.2307/1130689

Jurkovic, G. J. (1997). Lost childhoods: The plight of the parentified child. NY: Routledge.

Jurkovic, G. J., Kupermine, G. P., \& Casey, S. (2000). Filial responsibility scale-youth (Unpublished manuscript). Atlanta, GA: Georgia State University.

Kerig, P. K. (2005). Revisiting the construct of boundary dissolution: A multidimensional perspective. Journal of Emotional Abuse, 5(2-3), 5-42. doi:10.1300/J135v05n02_02

Minuchin, S. (1974). Families and family therapy. Cambridge, MA: Harvard University Press.

Peris, T. S., Goeke-Morey, M. C., Cummings, E. M., \& Emery, R. E. (2008). Marital conflict and support seeking by parents in adolescence: Empirical support for the parentification construct. Journal of Family Psychology, 22(3), 633-642. doi:10.1037/a0012792

Plunkett, S. W., Henry, C. S., Robinson, L. C., Behnke, A., \& Falcon, P. C. (2007). Adolescent perception parental behavior, adolescent self-esteem, adolescent depressed mood. Journal of Child and Family Studies, 16(6), 760-772. doi:10.1007/s10826-006-9123-0

Wells, M., \& Jones, R. (2000). Childhood parentification and shameproneness: A preliminary study. The American Journal of Family Therapy, 28(1), 19-27. doi:10.1080/019261800261789

\section{In Korean}

Ahn, J.-M., \& Ahn, K.-S. (2012). A study on related factors for adolescent's anger emotional experience. Korean Journal of 
Youth Studies, 19(3), 267-292. Retrieved from http://www. dbpia.co.kr/Journal/ArticleDetail/NODE06661882

Ahn, S.-S. (2014). The influence of parents' marital conflicts and early maladaptive schemas on behavior problems in children and adolescents (Master's thesis). Retrieved from http://www.riss. $\mathrm{kr} / \mathrm{link}$ ?id=T13391404

Chae, Y.-K. (2001). Verification on the model of expression modes and moderating effect of adolescents's anger (Doctoral dissertation). Retrieved from http://www.riss.kr/link?id=T8932930

Cho, E. (2004). The study of parentified children's psychological characteristics and power in their family (Doctoral dissertation). Retrieved from http://www.riss.kr/link?id=T9534707

Choi, M.-K. (2012). The relationship between marital conflict, parental control, and adolescents' anxiety. Korean Journal of Child Studies, 33(5), 163-180.

Choi, M. S., \& Kang, J. H. (2008). The effect of parentification on depression and anxiety in adolescents. Korean Journal of Play Therapy, 11(1), 43-53.

Choi, S.-G. (2017). The moderating effects of mindfulness on the relationship between high school girl's perfectionism and test anxiety (Master's thesis). Retrieved from http://www.riss.kr/ link?id=T14406732

Choi, W.-K. (2004). A study on the socio-structural cause of youth suicide. Social Welfare Policy, 18(4), 5-30.

Eoh, Y. (2005). (The) effects of the vulnerable family on the depression and behavioral problems of adolescents: The protective effect of social supports and personal features (Master's thesis). Retrieved from http://www.riss.kr/link?id=T9988510

Han, N., Lee, S., \& Row, K.-R. (2014). The relationship among behavioral inhibition system, perceived parenting behavior and anxiety of middle school students. Korean Journal of Youth Studies, 21(2), 327-348. Retrieved from http://www. riss.kr/link?id=A102952622

Ham, G. S. (2015). Mediating effects of perfectionism on the relation of middle school students' parentification and social anxiety (Master's thesis). Retrieved from http://www.riss.kr/ link? id=T13667649

Hwang, G. S. (2000). (A) study on the effects of parents' conflicts on their children's school performances and emotional adaptability (Master's thesis). Retrieved from http://www.riss.kr/ link?id=T8141031

Jang, J. (2006). The influence of marital conflict on children's maladaptation: Focusing on ego-resiliency, parent's child-rearing attitudes and social support (Master's thesis). Retrieved from http://www.riss.kr/link?id=T10878300

Jo, A. (2011). The effects of parental marital conflict and attachment on maladjustment behavior of adolescents: The moderating effect of self-esteem (Master's thesis). Retrieved from http:// www.riss.kr/link?id=T12343727

Jo, A.-R. (2014). Moderating role of self-soothing ability In the relationship between parent's marital conflict on depression and anxiety (Master's thesis). Retrieved from http://www.riss.kr/ link?id=T13411273

Kang, S. I. (2007). A study on the educational implications of adolescent anxiety (Master's thesis). Retrieved from http:// www.riss.kr/link?id=T11039114

Kang, S.-M. (2014). Parentification as a mediator between marital conflict and shame. Korean Journal of Youth Studies, 21(4), 257-283. Retrieved from http://www.dbpia.co.kr/Journal/ ArticleDetail/NODE06662220

Kim, B. Y. (2008). A meta-analysis of the variables related to adolescents' suicidal adolescents' suicidal ideation (Master's thesis). Retrieved from http://www.riss.kr/ link?id=T11315206

Kim, J. (2011). The effect of perceived marital conflicts on psychosocial maladjustment: The mediating role of parentification (Master's thesis). Retrieved from http://www.riss.kr/ link? id=T12281347

Kim, J. H. (2017). The effect of peer victimization on social anxiety in middle school students and the mediating role of selfconcept (Master's thesis). Retrieved from http://www.riss.kr/ link?id=T14451080

Kim, J. T. (1978). A study of the relationship between trait anxiety and social tendency (Unplished master's thesis). Korea University, Seoul, Korea.

Kim, J.-Y. (2007). The effects of preschooler's temperament, marital conflict and preschooler's emotion regulation on problem behavior (Master's thesis). Retrieved from http://www.riss. $\mathrm{kr} /$ link?id=T11038811

Kim, K. M., Lee, H. N., Jung, J. R., Jung, H. J., \& Lee, K. (2006). The effect of parentification on conflictual independence from parents, self-assertiveness, and ambivalence over emotional expressiveness. The Korean Journal of School Psychology, 3(1), 19-32. Retrieved from http://www.dbpia. co.kr/Journal/ArticleDetail/NODE06372284

Kim, M., \& Kim, J. (2013). A study on the influencing mental health factors to suicidal ideation in adolescents. Korean Journal of Youth Studies, 20(12), 267-293. Retrieved from http://www.riss.kr/link?id=A102952590

Kim, M. H. (2017). The relationship with parentification experience of adolescents, interpersonal problem and perfectionism (Master's thesis). Retrieved from http://www.riss.kr/ link?id=T14406568

Kim, M.-S. (2006). (The) relationship of parents' marital conflicts perceived by the 6th grade parent-child communication and depression (Unpublished master's thesis). Kyungsung University, Pusan, Korea.

Kim, N.-Y. (2016). A study on the children's problem behavior with parental conflict. Korean Journal of Youth Studies, 23(6), 27-46. 
Kim, Y. T. (2000). Family therapy theories: Concepts and methods. Seoul: Hakjisa.

Ko, A. (2007). The effects of highschool students' perceive parentadolescence communication, ego-resiliency on psychosocial adjustment (Master's thesis). Retrieved from http://www. riss.kr/link?id=T11220088

Kwon, Y. O., \& Lee, J. D. (1997). A validation study on the children's perception of interparental conflict scale. Korean Journal of Child Studies, 18(1), 65-80. Retrieved from http://childstudies.org/upload/pdf/31200255.pdf

Kwon, Y. O., \& Lee, J. D. (1999). Martial conflict and children's behavior problems. Korean Journal of Child Studies, 20(1), 115-133. Retrieved from http://www.childstudies.org/ upload/pdf/31200472.pdf

Lee, J. S. [Jeong Soo]. (2006). The influence of mother and peer attachment on adolescent's depression-the mediating effect of self-esteem (Master's thesis). Retrieved from http://www.riss. $\mathrm{kr} / \mathrm{link}$ ?id=T10532497

Lee, J.-S. [Jeong-Soon]. (2010). Parenting behavior, preschooler's behavior and preschooler's emotionally unstable behavior: Relationship to husband-wife relationship. Early Childhood Education Research \& Review, 14(3), 37-56.

Lee, J.-S. [Jung-Sook]., \& Kim, E.-K. (2007). Effect of juveniles' experience of being abused on their shame-proneness and parentification. The Korean Journal of Counseling and Psychotherapy. 19(2), 339-356. Retrieved from http://www. riss.kr/link?id=A100630470

Lee, J. Y. (2017). The influence of parents' marital conflict on children's interpersonal competence as college students: The mediating effects of the parentification, shame-proneness and co-dependency (Master's thesis). Retrieved from http://www. riss.kr/link? id $=\mathrm{T} 14434620$

Lee, S.-M., \& Yoo, S.-K. (2013). The relationship between peer victimization and depression/anxiety: meditating effects of passive/evasive behavior and aggressive behavior. Korea Journal of Counseling, 14(2), 1209-1226.

Lee, Y. J. (2013). The mediating effects of shame on the relationships between maladaptive perfectionism and social anxiety (Master's thesis). Retrieved from http://www.riss.kr/ link?id=T13054403

Lim, J., \& Yoon, J. (2010). A review of interparental conflict in relation to child developmental outcomes in Korean journals. The Korean Journal of the Human Development, 17(1), 263284. Retrieved from http://www.newnonmun.com/article= 21240

Moon, D.-K., \& Kim, Y.-H. (2011). A meta-regression analysis on related triggering variables of adolescents' suicidal ideation. Korea Journal of Counseling, 12(3), 945-964. Retrieved from http://www.riss.kr/link?id=A99780253

Moon, S. H. (2014). Mediating effects of ambivalence over emotional expression on the relation between parentification and wellbeing in adolescents (Master's thesis). Retrieved from http:// www.riss.kr/link? id=T13411651

Oh, S. (2017). The relation between parent's marital conflict and interpersonal problem by the college student children: The mediating effects of parentification and self-differentiation (Master's thesis). Retrieved from http://www.riss.kr/ link?id=T14437098

Park, S. J. (1996). The effect of parent's conflict on and children's psychological adjustment (Unpublished Master's thesis). Yonsei University, Seoul, Korea.

Park, S. Y., Lee, E. G., Song, J. H., \& Soenens, B. (2008). The effects of two types of parental psychological control on dependency, self-criticism and depression in adolescents. Korean Journal of Child Studies, 29(5), 65-78. Retrieved from http://childstudies.org/upload/pdf/31201509.pdf

Park, Y. S. (2016). A counseling case study of parentification on middle school student (Master's thesis). Retrieved from http://www.riss.kr/link?id=T14021808

Roh, Y. O. (2005). A study on the communication between parentschildren \& perceived marital conflict by children of adolescent (Master's thesis). Retrieved from http://www.riss.kr/ link?id=T10384433

Shin, M.-J., \& Ha, E. H. (2010). The mediating effects of negative cognition in the relationships between mothers' overprotective parenting attitudes and adolescents anxiety. The Korean Journal of Counseling and Psychotherapy, 22(2), 459-477. Retrieved from http://www.dbpia.co.kr/Journal/ ArticleDetail/NODE06369776

Son, H. M. (2007). The effect of marital conflict on parentification in graduates (Master's thesis). Retrieved from http://www.riss. $\mathrm{kr} /$ link?id=T11220181

Song, E. H. (2005). The influence of marital conflicts on children's psychological adjustment problems: The mediating effects $f$ cognitive-contextual appraisal and child (Master's thesis). Retrieved from http://www.riss.kr/link?id=T9843749

Song, E. J. (2010). Impact of marital conflicts on youth depression: through the parameter of parentification (Master's thesis). Retrieved from http://www.riss.kr/link?id=T12028919

Yoo, S. H. [Seoung Hee]. (2001). Connection between children's perception and self-consciousness by parents' trouble (Master's thesis). Retrieved from http://www.riss.kr/link?id=T10207474

Yoo, S. H. [Soon Hwa]. (2010). Relationship between parentification and well-being of adolescents. Korean Journal of Youth Studies, 17(10), 233-252. Retrieved from http://www.dbpia. co.kr/Journal/ArticleDetail/NODE06661631

Yoon, J. W. (2010). The relationship between dysfunctional beliefs and self-focused attention and speech anxiety from middle school students (Master's thesis). Retrieved from http://www. riss.kr/link?id=T12115401 
Yoon, K. M. (2011). The relationship between marital conflict and child-rearing attitude perceived by the mother and the child's adjustment (Master's thesis). Retrieved from http://www. riss.kr/link?id=T12578786

\section{ORCID}

Han-Na Yang Mi-Kyung Choi http://orcid.org/0000-0002-6577-7270

http://orcid.org/0000-0001-6026-1374

Received April 30, 2017

Revision received June 6, 2017

Accepted June 19, 2017 